\title{
French Maritime Pine Bark Extract (Pycnogenol ${ }^{\circledR}$ ) Effects on Human Skin: Clinical and Molecular Evidence
}

\author{
Susanne Grether-Beck Alessandra Marini Thomas Jaenicke Jean Krutmann
}

IUF, Leibniz Research Institute for Environmental Medicine, Düsseldorf, Germany

\section{Key Words}

Pycnogenol $^{\circledR} \cdot$ Pine bark extract · Pigmentation · Skin barrier

\begin{abstract}
Nutritional strategies to benefit skin health are of growing importance. Current approaches mainly involve nutritional supplements containing antioxidants which were initially designed to protect human skin against ultraviolet radiation-induced damage. Within recent years, however, a growing number of studies suggests that the beneficial effects of these products clearly extend beyond photoprotection. In this review we take the nutritional supplement Pycnogenol ${ }^{\circledR}$, which is based on an extract prepared from French marine pine bark extract, as an example to illustrate this development. Accordingly, the existing data provide compelling evidence that Pycnogenol ${ }^{\circledR}$ intake does not only provide photoprotection, but may be used to (i) reduce hyperpigmentation of human skin and (ii) improve skin barrier function and extracellular matrix homeostasis.
\end{abstract}

(C) 2015 S. Karger AG, Basel

\section{Introduction}

Within recent years extensive research has been conducted to assess whether and how the oral intake of nutritional supplements and/or functional food products can affect human skin (for a recent monograph, please see Krutmann and Humbert [1]). Initially, many of these studies have focused on the capacity of such strategies to provide protection against harmful effects of ultraviolet (UV) radiation on human skin. From these studies it is now generally accepted that oral photoprotection in principle works, although the time kinetics to achieve measurable photoprotection as well as the magnitude of photoprotection that can be achieved markedly differ from those obtained after topical application of a regular sunscreen product as it requires up to 3 months of oral intake and resulting sun protection factor levels are moderate, although significant (reviewed in Stahl [2]). On the other hand, oral photoprotection is relatively easy to achieve (just take a pill per day) and more homogenous as compared with topical sunscreen application, which strongly depends on how carefully the sunscreen is topically applied. Even more importantly, these studies have provided proof of principle that the oral intake of selected food products may exert beneficial effects on human skin. It is thus tempting to speculate that such effects may extend far beyond UV protection of human skin. In this review paper, we will summarize the existing evidence supporting this statement by focusing on the French maritime pine bark extract $\left(\right.$ Pycnogenol $\left.^{\circledR}\right)$, i.e. a widely used nutritional supplement. Pycnogenol ${ }^{\circledR}$ is an extract from the Pinus pinaster bark which contains a variety of natural antioxidants including bioflavonoids, catechins, procy-

\section{KARGER}

E-Mail karger@karger.com

www.karger.com/spp
(C) 2015 S. Karger AG, Base

1660-5527/15/0291-0013\$39.50/0
Prof. Dr. Jean Krutmann

IUF, Leibniz Research Institute for Environmental Medicine Auf $m$ Hennekamp 50

DE-40225 Düsseldorf (Germany)

E-Mail Jean.Krutmann@IUF-Duesseldorf.de 
anidins and phenolic acids $[3,4]$. There is growing evidence that Pycnogenol ${ }^{\circledR}$ is not only well suited for photoprotection of human skin, but also that the oral intake of this substance affects a number of basic skin functions which are of relevance for the maintenance of healthy skin. In addition we have decided to focus on this particular nutritional supplement because studies on its efficiency have not only employed the assessment of skin physiological, but also of molecular parameters in vivo in human skin and thereby provided important insight into the underlying mode of action. We restrict this review to three major health effects associated with oral supplementation of Pycnogenol ${ }^{\circledR}$ : (i) prevention of UV radiation-induced skin damage, (ii) modulation of skin pigmentation and (iii) improvement of skin barrier function/extracellular matrix homeostasis, because they are supported by human in vivo studies. We thus do not discuss in vitro studies on the effects of Pycnogenol ${ }^{\circledR}$ on cultured skin cells because their clinical relevance remains to be shown, and we did not include studies on the topical application of Pycnogenol ${ }^{\circledR}$ on mouse or human skin either [5-7].

\section{Photoprotection of Human Skin by Oral Ingestion of Pycnogenol $^{\circledR}$}

A number of studies provide compelling evidence that oral supplementation with Pycnogenol ${ }^{\circledR}$ protects human skin against UV radiation. Accordingly, in a study on 21 fair-skinned volunteers, Saliou et al. [8] demonstrated that oral ingestion of $1.10 \mathrm{mg}$ or $1.66 \mathrm{mg} / \mathrm{kg}$ body weight/ day Pycnogenol ${ }^{\circledR}$ is effective in reducing UV-induced erythema. In this study, the UV protective effect of Pycnogenol ${ }^{\circledR}$ was found to be dose dependent, to develop after 4-8 weeks of oral intake and to almost double the individual minimal erythema dose which was determined prior to Pycnogenol ${ }^{\circledR}$ intake. The strength of this study is the intraindividual comparison of minimal erythema doses before, during and after Pycnogenol ${ }^{\circledR}$ intake as well as the observed dose dependency of minimal erythema dose increases. Weaknesses of the study include the lack of a placebo treatment, e.g. in a crossover design or a comparator group. Although the study has been conducted during winter/spring time [S. Hosseini, pers. commun.], the study has not been controlled for the seasonal increase in exogenous antioxidants in the regular diet which is often observed during summer and autumn $[9,10]$. Also, it should be noted that solar radiation-induced erythema responses mainly result from the formation of DNA pho- toproducts such as cyclobutane pyrimidine dimers in human skin, which can be reduced by antioxidants only to some extent. In other words, photoprotection by Pycnogenol ${ }^{\circledR}$ might be even greater than observed here, if other biological end points, which more strongly depend on UV radiation-induced oxidative damage, would have been studied. Accordingly, oral ingestion of the carotenoid lycopene was previously shown to only moderately reduce solar UV radiation-induced erythema by $37 \%$ [11], whereas long-wave UVA radiation-induced gene transcription, which strictly depends on the generation of reactive oxygen species in human skin, was almost completely inhibited [12]. It should also be noted that in vivo animal studies show that oral ingestion by mice significantly reduces the number and growth rate of skin tumors which were induced either by chronic UVB irradiation or by a combination of UVB radiation with topical treatment of skin with the polyaromatic hydrocarbon 7,12-dimethylbenzanthracene [13]. As UVB- as well as polyaromatic hydrocarbon-mediated skin carcinogeneses both critically involve activation of the aryl hydrocarbon receptor (AHR; reviewed in Haarmann-Stemmann et al. [14]) and since flavonoids such as catechin and epicatechin, which are a main constituent of Pycnogenol ${ }^{\circledR}$, have been shown to inhibit AHR activation [15], it is tempting to speculate that oral ingestion of Pycnogenol ${ }^{\circledR}$ may help to suppress environmentally induced AHR activation in skin cells.

\section{Modulation of Skin Pigmentation by Oral Ingestion of Pycnogenol ${ }^{\circledR}$}

There is now also more and more evidence that Pycnogenol ${ }^{\circledR}$ may affect pigmentation of human skin. In 2002, Ni et al. [16] were first to provide evidence that Pycnogenol ${ }^{\circledR}$ intake may reduce hyperpigmentation in women with melasma. In this study, a total of 30 Chinese female patients with melasma orally ingested $75 \mathrm{mg}$ Pycnogenol ${ }^{\circledR} /$ day for a total of 1 month. The impact of Pycnogenol ${ }^{\circledR}$ intake on preexisting melasma was assessed by means of a clinical score, i.e. the melasma area index, which was based on assessing the diameter of the lesional skin area by means of a ruler. In addition, the pigmentary intensity index was determined by means of a color chart. It was found that after the 30-day treatment period both parameters were significantly reduced. Pycnogenol ${ }^{\circledR}$ was well tolerated in all patients, and standard blood and urine parameters did not change. The authors concluded that Pycnogenol ${ }^{\circledR}$ is therapeutically effective and safe in 


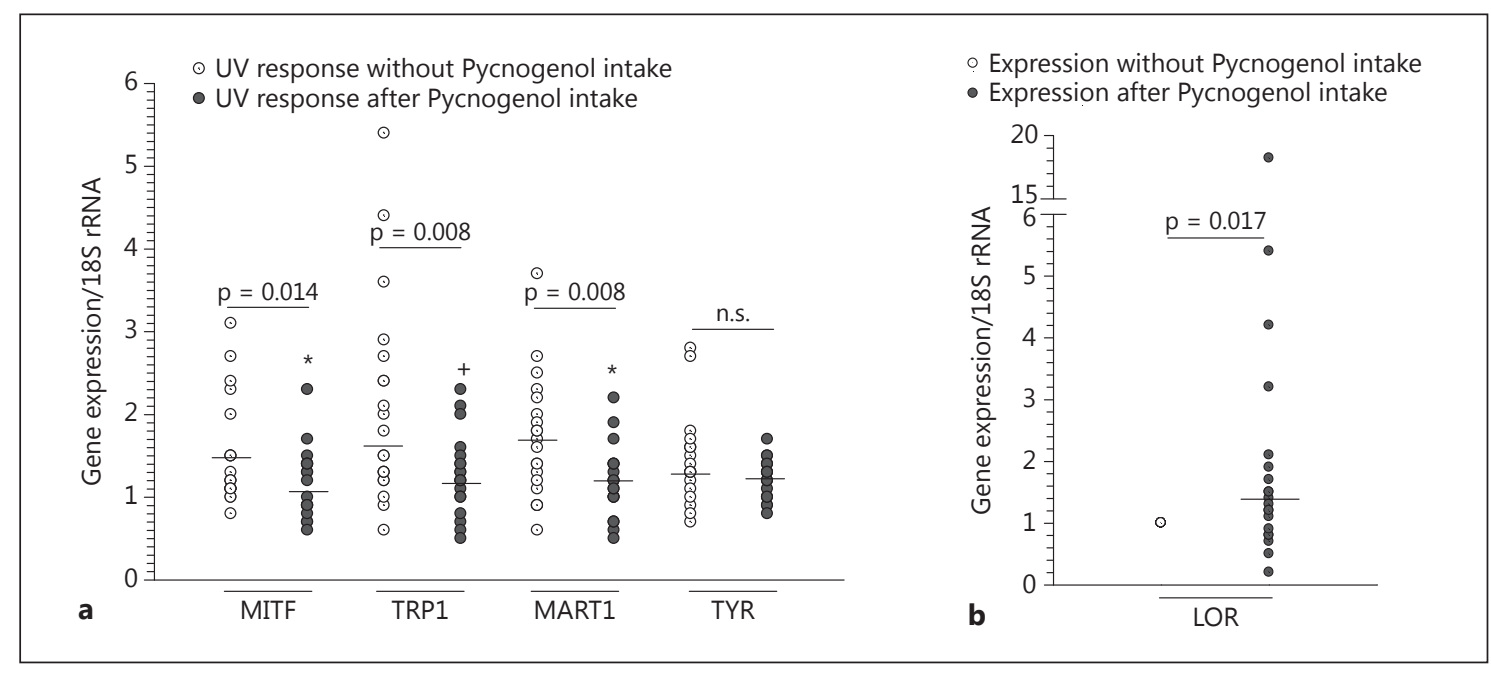

Fig. 1. a Gene expression of microphthalmia-associated transcription factor (MITF), tyrosinase-related protein 1 (TRP1), melanoma antigen recognized by T cells (MART1) and tyrosinase (TYR). Presented are UV responses detected as $\mathrm{n}$-fold increase compared to unirradiated skin before and after intake of dietary Pycnogenol ${ }^{\circledR}$ for 12 weeks in postmenopausal women $(n=19-20)$; a dash indicates the mean or median; statistical significance was evaluated by the paired t test $\left(^{*}\right)$ or Wilcoxon signed rank test $\left(^{+}\right)$. At the begin- ning and again after 12 weeks of Pycnogenol ${ }^{\circledR}$ supplementation, each time two 4-mm punch biopsies were obtained from (i) unirradiated and (ii) irradiated $\left(100 \mathrm{~J} / \mathrm{cm}^{2} \mathrm{UVA} 1\right)$ buttock skin for the assessment of gene expression of MITF, TRP1, MART1 and TYR. b Gene expression of loricrin (LOR) before and after Pycnogenol ${ }^{\circledR}$ intake in unirradiated skin. $\mathrm{n}=20$ postmenopausal women; a dash indicates the median; $\mathrm{p}<0.05$ by the Wilcoxon signed rank test. patients with melasma, and they attributed the observed beneficial effects to the well-known antioxidative properties of Pycnogenol ${ }^{\circledR}$ [16]. It has to be noted that the design of this study was open, and efficacy parameters were based on subjective assessments. Nevertheless, this study was first to indicate that Pycnogenol ${ }^{\circledR}$ intake might be effective to downregulate skin hyperpigmentation. In line with this assumption are in vitro experiments which showed that treatment of cells from the human melanoma cell line B16 with Pycnogenol ${ }^{\circledR}$ reduced tyrosinase activity and melanin synthesis in this tumor cell line [17]. Even more important are results from a recent human in vivo study which provide molecular evidence that the oral intake of Pycnogenol ${ }^{\circledR}$ downregulates the expression of genes in human skin which are critically involved in melanin synthesis. The design and part of the results of this clinical trial have previously been published in this journal [18]. This study is unique because it is the only one to provide in vivo molecular evidence that Pycnogenol ${ }^{\circledR}$ uptake is beneficial for human skin. In this clinical trial, a total of 20 healthy postmenopausal Caucasian women were supplemented with $3 \times 25 \mathrm{mg}$ Pycnogenol ${ }^{\circledR}$ daily for a total of 12 weeks. It was found that this intervention significantly improved skin elasticity and skin hydration, and that this improvement of skin physiological param- eters was associated with a significant upregulation of mRNA steady-state levels for hyaluronic acid synthase-1, an enzyme which is important for hyaluronic acid synthesis in skin, as well as genes involved in collagen de novo synthesis. Further RT-PCR analysis of RNA purified from biopsies obtained in this study additionally revealed a significant effect of intake of Pycnogenol ${ }^{\circledR}$ on the transcriptional expression of genes which are critically involved in skin pigmentation [19]. Accordingly, these yet unpublished data, which are here shown as figure 1a, demonstrate that oral Pycnogenol ${ }^{\circledR}$ intake was able to significantly inhibit UV radiation-induced upregulation of microphthalmia-associated transcription factor, tyrosinase-related protein 1 and melanoma antigen recognized by T cells, and mRNA expression of tyrosinase was inhibited by trend. These changes provide a molecular basis to explain the previous notion that Pycnogenol ${ }^{\circledR}$ intake benefits patients with melasma. The exact mechanism through which Pycnogenol ${ }^{\circledR}$ may inhibit the expression of genes involved in skin hyperpigmentation is currently not known. We previously discussed the possibility that Pycnogenol ${ }^{\circledR}$ may at least in part function by antagonizing AHR activation. In this regard it should be noted that AHR activation in human as well as murine melanocytes has recently been reported to be critically involved in UV 
radiation-induced skin pigmentation $[20,21]$. Specifically, AHR activation was shown to cause upregulation of tyrosinase-related proteins 1 and 2 as well as tyrosinase in primary human melanocytes. In aggregate, these studies indicate that the oral intake of Pycnogenol ${ }^{\circledR}$ may be used to reduce skin pigmentation in humans in general and hyperpigmentation caused by melasma in particular. Given the central role of microphthalmia-associated transcription factor in the pathogenesis of skin hyperpigmentation and pigmented skin lesions, this should prompt further controlled clinical trials to assess the effect of oral Pycnogenol ${ }^{\circledR}$ intake on pigment spot formation in chronically UV-exposed skin areas.

\section{Effects of Oral Pycnogenol ${ }^{\circledR}$ Intake on Skin Barrier Function/Extracellular Matrix Homeostasis}

There is also growing evidence that Pycnogenol ${ }^{\circledR}$ intake affects extracellular matrix homeostasis. It has been shown in a double-blind, placebo-controlled study that supplementation with Pycnogenol ${ }^{\circledR}$ in combination with vitamins and minerals improves skin smoothness and elasticity in women [22]. Similarly and as mentioned above, supplementation with Pycnogenol ${ }^{\circledR}$ alone also significantly improved skin elasticity, probably due to an increased expression of genes involved in collagen de novo as well as hyaluronic acid synthesis [18]. Matrix-degrading metalloproteinases are key mediators of collagen degradation observed in photoaged human skin [23]. In vitro studies indicated that some metabolites from the pine bark extract identified in human urine exhibit inhibitory activity on lipopolysaccharide-induced secretion of matrix metalloproteinase 9 in human monocytes [24, 25]. Also, in previous studies, oral supplementation of Pycnogenol ${ }^{\circledR}$ resulted in sufficient enrichment of active metabolites in human serum to moderately inhibit matrix metalloproteinase 9 secretion in human monocytes ex vivo not limited to the dermal compartment, but may also include epidermal barrier improvement. This assumption is supported by additional, yet unpublished data from the Marini study, which demonstrate an increased expression of genes involved in keratinocyte differentiation and barrier formation including loricrin, indicating the possibility that Pycnogenol ${ }^{\circledR}$ supplementation was associated with an improved formation of cornified envelopes

\section{Outlook}

As discussed above, Pycnogenol ${ }^{\circledR}$ supplementation is a good example for a nutritional supplement which has the potential to exert a variety of beneficial effects on human skin. In view of the recent demographic development, which is worldwide characterized by an extension of life expectancy, these observations are of great clinical relevance. In this regard, a regular intake of antioxidantbased nutritional supplements is relatively convenient and easy to achieve also by the elderly, who otherwise might have problems to use sufficient amounts of topical products over longer periods of time. Also, nutritional supplements, if taken regularly and for longer time periods, might significantly contribute to preserve skin health by protecting human skin against different environmental insults. As discussed, existing evidence strongly suggests that protection against UV radiation-induced skin damage including hyperpigmentation is possible. In this regard, the authors would like to see additional studies being done which take into account very recent evidence that skin damage in general and skin hyperpigmentation/ skin aging in particular can also be caused by other environmental factors such as nonionizing radiation in the visible as well as infrared range (reviewed in GretherBeck et al. [26]) and ambient air pollution including traffic-related particulate matter (reviewed in Krutmann et al. [27]).

\section{Disclosure Statement}

The original data shown in this report were derived from a study supported by Horphag Research, Cointrin/Geneva, Switzerland. [25].

In addition, Marini et al. [18] observed an increase in skin hydration indicating that Pycnogenol ${ }^{\circledR}$ effects are and thus skin hydration (fig. 1b).

References
1 Krutmann J, Humbert P (eds): Nutrition of Healthy Skin: Strategies for Clinical and Cosmetic Practice. Berlin, Springer, 2011.

2 Stahl W: Systemic photoprotection by carotenoids; in Krutmann J, Humbert P (eds): $\mathrm{Nu}$ trition for Healthy Skin: Strategies for Clinical and Cosmetic Practice. Berlin, Springer, 2011, pp 65-70.

3 Rohdewald P: A review of the French maritime pine bark extract (Pycnogenol), a herbal medication with a diverse clinical pharmacology. Int J Clin Pharmacol Ther 2002;40:158168.

4 Maritime pine extract; in United States Pharmacopeia. Rockville, United States Pharmacopeial Convention Inc, 2005, vol 28, pp 2115-2116. 
5 Sime S, Reeve VE: Protection from inflammation, immunosuppression and carcinogenesis induced by UV radiation in mice by topical Pycnogenol. Photochem Photobiol 2004;79: 193-198.

6 Blazso G, Gabor M, Schonlau F, Rohdewald P: Pycnogenol accelerates wound healing and reduces scar formation. Phytother Res 2004; 18:579-581.

7 Sarikakai V, Rallis M, Tanojo H, Panteri I, Dotsikas Y, Loukas Y, Papioannou G, Demetzos C, Weber S, Moini H, Maibach H, Packer $\mathrm{L}$ : In vitro percutaneous absorption of pine bark extract $\left(\right.$ Pycnogenol $\left.^{\circledR}\right)$ in human skin. J Toxicol Cutan Ocul Toxicol 2004;23:149148.

8 Saliou C, Rimbach G, Moini H, McLaughlin L, Hosseini S, Lee J, Watson RR, Packer L: Solar ultraviolet-induced erythema in human skin and nuclear factor-kappa-B-dependent gene expression in keratinocytes are modulated by a French maritime pine bark extract. Free Radic Biol Med 2001;30:154-160.

9 Darvin ME, Patzelt A, Knorr F, Blume-Peytavi U, Sterry W, Lademann J: One-year study on the variation of carotenoid antioxidant substances in living human skin: influence of dietary supplementation and stress factors. J Biomed Opt 2008;13:044028.

10 Darvin M, Sterry W, Lademann J, Vergou T: The role of carotenoids in human skin. Molecules 2011;16:10491-10506.

11 Heinrich U, Gartner C, Wiebusch M, Eichler $\mathrm{O}$, Sies H, Tronnier H, Stahl W: Supplementation with beta-carotene or a similar amount of mixed carotenoids protects humans from UV-induced erythema. J Nutr 2003;133:98101.
12 Grether-Beck S, Marini A, Jaenicke T, Krutmann J: Effect of nutritional lycopene on UV induced gene expression in human skin in vivo. Unpublished study.

13 Kyriazi M, Yova D, Rallis M, Lima A: Cancer chemopreventive effects of Pinus maritima bark extract on ultraviolet radiation and ultraviolet radiation-7,12-dimethylbenz(a)anthracene induced skin carcinogenesis of hairless mice. Cancer Lett 2006;237:234-241.

14 Haarmann-Stemmann T, Esser C, Krutmann $\mathrm{J}$ : The Janus faced role of aryl hydrocarbon receptor (AHR) signaling in skin: consequences for prevention and treatment of skin disorders. J Invest Dermatol 2015, Epub ahead of print.

15 Palermo CM, Hernando JI, Dertinger SD, Kende AS, Gasiewicz TA: Identification of potential aryl hydrocarbon receptor antagonists in green tea. Chem Res Toxicol 2003;16: 865-872.

$16 \mathrm{Ni}$ Z, Mu Y, Gulati O: Treatment of melasma with Pycnogenol. Phytother Res 2002;16: 567-571.

17 Kim YJ, Kang KS, Yokozawa T: The anti-melanogenic effect of pycnogenol by its anti-oxidative actions. Food Chem Toxicol 2008;46: 2466-2471.

18 Marini A, Grether-Beck S, Jaenicke T, Weber M, Burki C, Formann P, Brenden H, Schonlau F, Krutmann J: Pycnogenol ${ }^{\circledR}$ effects on skin elasticity and hydration coincide with increased gene expressions of collagen type I and hyaluronic acid synthase in women. Skin Pharmacol Physiol 2012;25:86-92.

19 Grether-Beck S, Marini A, Jaenicke T, Krutmann J: An intervention study to evaluate the in vivo cosmetic effects of a dietary supplement (Pycnogenol) in postmenopausal healthy women: additional gene expression studies. 2013.
20 Luecke S, Backlund M, Jux B, Esser C, Krutmann J, Rannug A: The aryl hydrocarbon receptor (AHR), a novel regulator of human melanogenesis. Pigment Cell Melanoma Res 2010;23:828-833.

21 Jux B, Kadow S, Luecke S, Rannug A, Krutmann J, Esser C: The aryl hydrocarbon receptor mediates UVB radiation-induced skin tanning. J Invest Dermatol 2011;131:203210.

22 Segger D, Schonlau F: Supplementation with Evelle improves skin smoothness and elasticity in a double-blind, placebo-controlled study with 62 women. J Dermatolog Treat 2004;15:222-226.

23 Quan T, Qin Z, Xia W, Shao Y, Voorhees JJ, Fisher GJ: Matrix-degrading metalloproteinases in photoaging. J Investig Dermatol Symp Proc 2009; 14:20-24.

24 Grimm T, Schafer A, Hogger P: Antioxidant activity and inhibition of matrix metalloproteinases by metabolites of maritime pine bark extract (Pycnogenol). Free Radic Biol Med 2004;36:811-822.

25 Grimm T, Chovanova Z, Muchova J, Sumegova $K$, Liptakova A, Durackova Z, Hogger P: Inhibition of NF-kappaB activation and MMP-9 secretion by plasma of human volunteers after ingestion of maritime pine bark extract (Pycnogenol). J Inflamm (Lond) 2006; 3:1.

26 Grether-Beck S, Marini A, Jaenicke T, Krutmann J: Photoprotection of human skin beyond ultraviolet radiation. Photodermatol Photoimmunol Photomed 2014;30:167-174.

27 Krutmann J, Liu W, Li L, Pan X, Crawford M, Sore G, Seite S: Pollution and skin: from epidemiological and mechanistic studies to clinical implications. J Dermatol Sci 2014;76:163168
Pycnogenol ${ }^{\circledR}$ : Clinical and Molecular Evidence for Skin Protection
Skin Pharmacol Physiol 2016;29:13-17 DOI: $10.1159 / 000441039$ 